\title{
Dynamics of physiological characteristics and dry matter accumulation under rain-water storage irrigation
}

\author{
Yuanyuan $\mathrm{Li}^{1 *}$, Xiaohou Shao ${ }^{2}$, Yanbin $\mathrm{Li}^{1}$, Menghua Xiao ${ }^{3}$ \\ (1. School of Water Conservancy, North China University of Water Resource and Electric Power, Zhengzhou 450045, China; \\ 2. College of Water Conservancy and Hydropower, Hohai University, Nanjing 210098, China; \\ 3. Rural Water Conservancy Research Institute, Zhejiang Institute of Hydraulics and Estuary, Hangzhou 310020, China)
}

\begin{abstract}
Photosynthesis is related to dry matter accumulation in aboveground part of rice plant, which is the direct factor of production. This study carried out research on physiological indicators and the relationship between photosynthesis and dry matter accumulation under different water management in paddy field. In general, the photosynthetic and physiological indicators showed the trend of increasing and then decreasing with the growth stage of rice. Experimental results showed that, chlorophyll content and leaf area index of rice leaves showed a quadratic curve positive correlation. Canopy light transmission reached the maximum at heading-flowering stage, and it had quadratic relationship with leaf area index, while it showed extremely positive correlation under rain-water storage irrigation mode. Photosynthetic rate $\left(P_{n}\right)$ and transpiration rate $\left(T_{r}\right)$ had quadratic curve positive correlation with chlorophyll content. The water condition under rain-water storage was favorable for dry matter accumulation in panicle. After multiple regression and main factor analysis, canopy light transmission, light transmission coefficient and $P_{n}$ were main factors related to dry matter accumulation. The conclusions in this article were helpful for promoting rice yield in practice.
\end{abstract}

Keywords: physiological index, dry matter accumulation, canopy light transmission, regression analysis DOI: $10.25165 /$ j.jjabe.20211403.5771

Citation: Li Y Y, Shao X H, Li Y B, Xiao M H. Dynamics of physiological characteristics and dry matter accumulation under rain-water storage irrigation. Int J Agric \& Biol Eng, 2021; 14(3): 148-155.

\section{Introduction}

As one of the most important physiological processes of crops, photosynthesis is sensitive to field water condition ${ }^{[1]}$. The formation of crops mainly comes from the accumulation and distribution of photosynthesis products. The characteristic of photosynthetic index is different under different water condition ${ }^{[2-4]}$. Therefore, studies on the growth and photosynthetic characteristics of rice could definite the physiological status and predict the production potential of rice plants. Carroll et al. ${ }^{[5]}$ have found that leaf area decreased under drought condition. $\mathrm{Xu}$ et al. ${ }^{[6]}$ found that net photosynthetic rate decreased with the decreasing of soil moisture, and the difference between different soil water content became bigger when the light intensity was higher than $400 \mu \mathrm{mol} /\left(\mathrm{m}^{2} \cdot \mathrm{s}\right)$, however, it could be recovered after re-watering. The similar results were concluded for other researcher ${ }^{[7]}$. The similar results were found by $\mathrm{Wu}$ et al. ${ }^{[8]}$ and Cui et al. ${ }^{[9]}$ that photosynthetic rate was improved by increasing soil water content. However, photosynthetic rate was negatively affected by water deficit during flowering stage, resulting in leaf senescence ${ }^{[8,10]}$. $\mathrm{Xu}$ et al. ${ }^{[11]}$ also found the growth of rice plants under soil moisture

\section{Received date: 2020-03-11 Accepted date: 2021-01-26}

Biographies: Xiaohou Shao, $\mathrm{PhD}$, Professor, research interest: agricultural water-saving technique and soil moisture management, Email: shaoxiaohou@163.com; Yanbin Li, PhD, Professor, research interest: efficient use of water resources, Email: liyb101@sina.com; Menghua Xiao, PhD, Associate Professor, research interest: reclaimed water utilization, Email:menghuaxiao@aliyun.com.

*Corresponding author: Yuanyuan Li, PhD, Researcher, research interest: agricultural water and soil environment protection. North China University of Water Resource and Electric Power, Zhengzhou 450045, China. Tel: +86-15903662916, Email: liya66720@126.com. control was restricted. Peng et al. ${ }^{[12]}$ found that daily maximum transpiration rate was delayed with when soil moisture decreased. The transpiration rate under controlled irrigation was lower than that under conventional irrigation, and it rebounded after re-watering. Farooq et al. ${ }^{[13]}$ found that decreasing of transpiration rate resulted in the reduction in biomass accumulation. $\mathrm{Du}$ et al. ${ }^{[14]}$ found that net photosynthetic rate was positively correlated with transpiration rate. Wang et al. ${ }^{[15]}$ considered that control irrigation could promote rice tillering and increase dry matter accumulation of roots. Peng et al. ${ }^{[16]}$ and Liu et al. ${ }^{[17]}$ found dry matter accumulation under water deficit was significantly decreased during late jointing-booting and heading-flowering stages compared to control treatment, and also appropriate leaf area index was remained to intercept more light under controlled irrigation. However, Lei et al. ${ }^{[18]}$ and Zhu et al. ${ }^{[19]}$ found that dry matter accumulation before jointing stage decreased under controlled irrigation during tillering stage, while the net photosynthetic rate and leaf area index at later growth stage increased. The leaf area index, net photosynthetic rate, transpiration rate, accumulation and allocation of photosynthate under non-sufficient irrigation treatment were lower than those of conventional irrigation treatment at early crop stage, while the compensation effect under non-sufficient irrigation was obvious at late stage ${ }^{[20]}$.

In south China, rain is abundant during the growth season of rice, therefore, rain-water storage irrigation is developed as an important water-saving technique in rain-fed regions. Guoth et al. ${ }^{[21]}$ and Liu et al. ${ }^{[22]}$ found photosynthesis and dry matter accumulation were improved with efficiency utilization of rainwater. Shahazad et al. ${ }^{[23]}$ found that the photosynthetic characteristics were positively correlated with the dry matter translocation, soil water content and grain yield. In this article, 
according to analysis on change law of photosynthetic and physiological index and dry matter accumulation under rain-storage irrigation, rainfall was made the best use of and it also provided a theoretical basis on improving rice yield.

\section{Materials and methods}

\subsection{Experimental site}

This test area was located at Vegetables (Flowers) Scientific Institute, (latitude $31^{\circ} 43^{\prime} \mathrm{N}$, longitude $118^{\circ} 46^{\prime} \mathrm{E}$ ), Jiangning District of Nanjing City, Jiangsu Province in China during rice growing season from June to October in 2013 and 2015. The experimental site has an average annual rainfall of approximately $1107 \mathrm{~mm}$, 2017 sunshine hours, average annual temperature of about $15.7^{\circ} \mathrm{C}$, average yearly evaporation of about $1473 \mathrm{~mm}$, and maximum average humidity was $81 \%$.

The paddy field soil was clayey loam, with organic matter of $21.7 \mathrm{~g} / \mathrm{kg}$, field capacity of $28 \%, \mathrm{pH}$ of 5.87 , bulk density of $1.35 \mathrm{~g} / \mathrm{cm}^{3}$, hydrolysis nitrogen of $86.5 \mathrm{mg} / \mathrm{kg}$, and available phosphorus of $25.3 \mathrm{mg} / \mathrm{kg}$ at the $0-60 \mathrm{~cm}$ soil layer.

\subsection{Experiential design}

Paddy rice (Oryza sativa L. cv. Kaohsiung 139) was grown in test area using the random block method with three replications of equal size $(2 \mathrm{~m} \times 5 \mathrm{~m})$. Two water irrigation schemes were set up in this study, conventional irrigation (CVI) and rain-water storage irrigation (RSI). All experimental plots were treated with the same fertilizer management. Basal fertilizer was applied before rice transplantation according to local practice, with total nitrogen of $193 \mathrm{~kg} / \mathrm{hm}^{2}$ and $214 \mathrm{~kg} / \mathrm{hm}^{2}$ in 2013 and 2015, $\mathrm{P}_{2} \mathrm{O}_{5}$ of $134 \mathrm{~kg} / \mathrm{hm}^{2}$, and $\mathrm{K}_{2} \mathrm{O}$ of $120 \mathrm{~kg} / \mathrm{hm}^{2}$, respectively. Then dressing nitrogen fertilizer was applied at tillering and heading-flowering stages, accounting for $70 \%$ and $30 \%$ of basal nitrogen fertilizer amount, respectively. Each plot received separate irrigation water, drainage, water meter, and lysimeter, while all the plots shared one rain gauge. Polyethylene sheets were used around the bunds of each plot to prevent lateral seepage loss. The experimental site layout is shown in Figure 1.

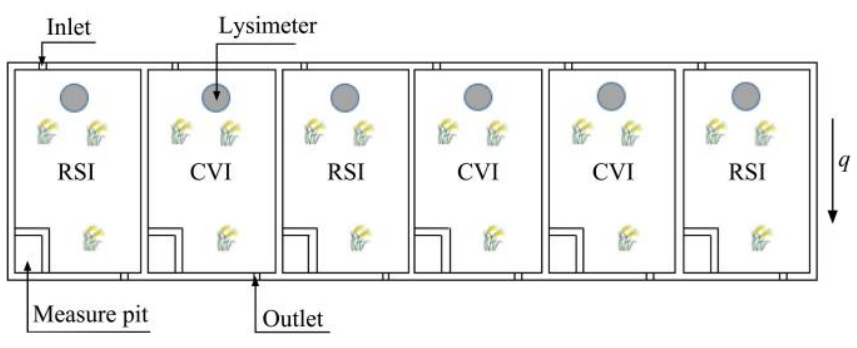

Figure 1 Experimental site layout

For rain-water storage irrigation, both paddy soil moisture and rainfall amount were considered as the controlling targets for irrigation regime after the green-returning stage. Depending on different growth stages of the paddy rice, the lower limit was $60 \%-80 \%$ of saturated water content, while the upper control limit of soil moisture was the saturated water content during irrigation, with no field water layer after the re-greening stage. If precipitation happened, the upper limit of rain ceiling storage was controlled at 20-70 $\mathrm{mm}$ according to different growth stages (Table 1). The main advantage for rain-water storage irrigation is making full use of natural rain-water compared to conventional irrigation treatment.

Table 1 Controlling targets of soil moisture during paddy rice growth stages in two irrigation regimes

\begin{tabular}{|c|c|c|c|c|c|c|c|}
\hline \multirow{2}{*}{ Treatment } & \multirow{2}{*}{ Re-greening } & \multicolumn{3}{|c|}{ Tillering } & \multirow{2}{*}{ Jointing-booting } & \multirow{2}{*}{ Heading-flowering } & \multirow{2}{*}{ Milking } \\
\hline & & Early & Mid-term & Late & & & \\
\hline RSI & $\begin{array}{l}100 \% \\
(5-25)\end{array}$ & $\begin{array}{c}70 \% \\
(0-50)\end{array}$ & $\begin{array}{c}65 \% \\
(0-50)\end{array}$ & $\begin{array}{l}60 \% \\
(0-0)\end{array}$ & $\begin{array}{c}80 \% \\
(0-70)\end{array}$ & $\begin{array}{c}80 \% \\
(0-70)\end{array}$ & $\begin{array}{c}65 \% \\
(0-20)\end{array}$ \\
\hline CVI & $\begin{array}{c}100 \% \\
(30-50)\end{array}$ & $\begin{array}{l}100 \% \\
(0-30)\end{array}$ & $\begin{array}{c}100 \% \\
(15-30)\end{array}$ & $\begin{array}{l}60 \% \\
(0-0)\end{array}$ & $\begin{array}{c}100 \% \\
(30-50)\end{array}$ & $\begin{array}{c}100 \% \\
(30-50)\end{array}$ & $\begin{array}{c}100 \% \\
(15-30)\end{array}$ \\
\hline
\end{tabular}

Notes: (1) The first number is a percentage of the saturated water content of soil. (2) The numbers in parenthesis is a range of the storage depth of surface water in mm in the paddy field.

\subsection{Indicators and methods}

Chlorophyll content of rice leaves was measured by chlorophyll meter (CCM200, USA) at 10:00 on sunny days with sun. 10 rice plants were selected randomly to measure the chlorophyll content of maximum functional leaf from tillering stage, and then taking the average.

Leaf area index was measured in synchronization with the light transmission amount by canopy analyzer (Sunscan, UK) at 10:00 on sunny days with sun. The canopy analyzer was placed between two rows of rice plants when measuring, and the probe was set to the north-south direction. The level of tripod and the probe should be ensured.

Photosynthetic rate and transpiration rate were measured by photosynthetic instrument (TPS-2, USA) at 11:00 on sunny day with sufficient sunshine. The instrument was placed vertically when measuring, and leaf at the same position was selected with the light intensity controlled at $800 \mu \mathrm{mol} /\left(\mathrm{m}^{2} \cdot \mathrm{s}\right)$.

Dry matter accumulation in aboveground part was measured by selecting three representative plants, and then the stems, leaves and spike were cleaned separately before being killed out in the drying cabinet at $105^{\circ} \mathrm{C}$ for $1 \mathrm{~h}$. After that, the rice plants were dried in an oven at $80^{\circ} \mathrm{C}$ to constant weight. In the end, the rice plant biomass of each part was weighed by a balance ${ }^{[24]}$.

\subsection{Statistical analysis}

Simple data calculation and diagramming were completed by Excel 2013. Correlation and regression analysis were carried out by SPSS Statistics 19. The variance homogeneity of the ANOVA was tested before ANOVA analysis.

\section{Results}

3.1 Dynamic change of leaf area index and chlorophyll content

At the beginning of the tillering stage, the absorption ability of water and fertilizer was enhanced for rice roots because of rapid vegetative growth of rice with sufficient soil nutrients, bringing about increase of leaf area index (Figure 2). The leaf area index reached the maximum at Day 65 and Day 60 after transplantation respectively in 2013 and 2015, followed by decreasing with leaf senescence of rice. The leaf area index continued to decrease at the milking stage with the nutrient supply stop. In 2013, the maximum leaf area index of rice under the conditions of RSI and CVI were 2.4 and 2.2, respectively, and they were 2.5 and 2.3 in 2015 , respectively, which showed that there was little difference in leaf area index between the different water treatments.

Comparing the changes of chlorophyll content in rice leaves 
(Figure 3), it was clear that there was not much difference under two irrigation modes, and the absolute value of the difference (D-value) did not exceed 2.0. In general, the change trend of chlorophyll content was consistent with that of leaf area index, with rapidly increase during the re-greening period. From the tillering stage, it gradually increased slowly and then decreased slowly, reaching the maximum at Day 65 and Day 60 after transplantation in 2013 and 2015, respectively. The maximum chlorophyll content under RSI and CVI in 2013 was 21.0 and 22.8, respectively, and in 2015 it was 32.2 and 33.1, respectively. The results of variance analysis showed that the effect of the irrigation method on chlorophyll content of rice leaves was not obvious $(p>0.05)$. The variation of D-value for chlorophyll content under two irrigation modes showed the jagged trend of stepwise increasing and then decreasing.

At the early stage of rice growth, the leaves were smaller and the chlorophyll content was lower. The average chlorophyll content of RSI and CVI treatments was 9.9 and 15.1 in 2013 and
2015, with relatively lower content under RSI treatment compared to CVI. After that, with the rice plant growth and increase of tillering, the leaves increased gradually, resulting in photosynthesis increasing gradually. The chlorophyll content of RSI surpassed that of CVI at $45 \mathrm{~d}$ for a short while, and the chlorophyll content reached the maximum at heading-flowering stage. After that, with the senescence of rice leaves, the chlorophyll content decreased rapidly. Eventually, the chlorophyll content decreased to the initial level at the early tillering stage, which was slightly higher than that at the re-greening period.

Both chlorophyll content and leaf area index are important parameters of rice leaves, which are closely related to dry matter accumulation in rice plants. Correlation analysis between chlorophyll content $(y)$ and leaf area index $(x)$ of rice leaves showed a quadratic curve positive correlation (Figure 4). The regression equation in 2013 was $y=-0.183 x^{2}+8.411 x+4.309$, the correlation coefficient $R^{2}=0.770$; the regression equation in 2015 was $y=-1.880 x^{2}+$ $15.384 x+3.703$, and the correlation coefficient $R^{2}=0.855$.

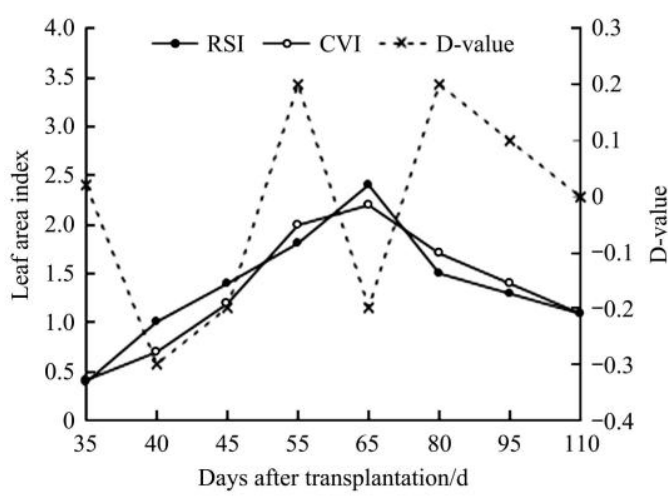

a. Year 2013

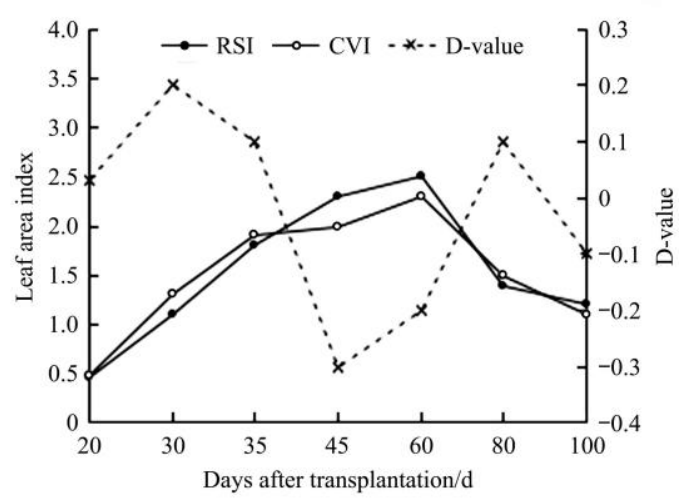

b. Year 2015

Figure 2 Dynamics of leaf area index under different irrigation modes

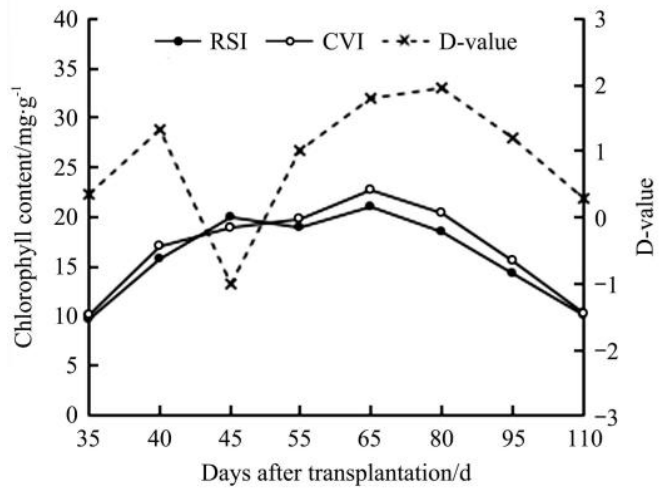

a. Year 2013

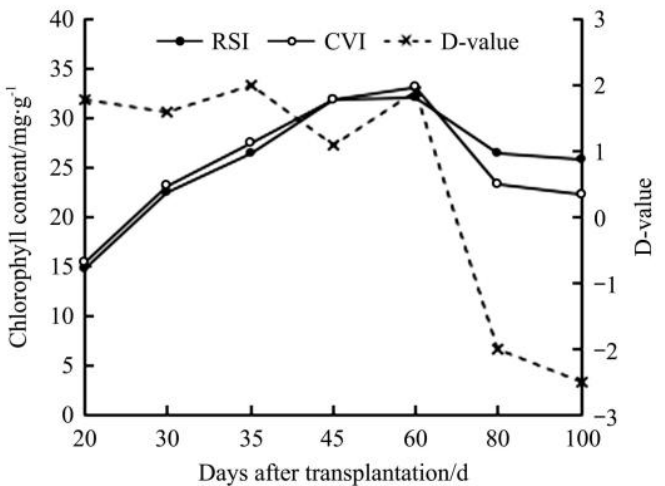

b. Year 2015

Figure 3 Dynamics of chlorophyll content under different irrigation modes
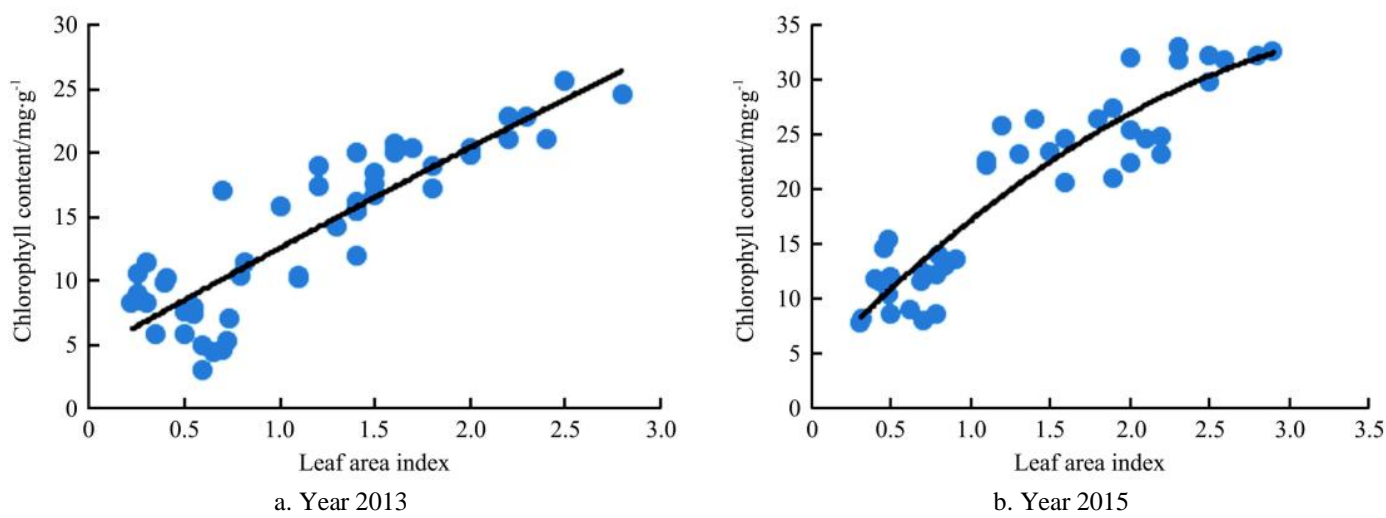

Figure 4 Regression analysis on chlorophyll content and leaf area index 


\subsection{Dynamic change of canopy light transmission}

The canopy morphology is an important factor affecting the light distribution and photosynthetic characteristics of crop, which could affect the interception, absorption and transmission of photosynthetically active radiation.

The change trend of light transmission coefficient of rice canopy and light transmission amount for RSI and CVI treatments was similar, and they varied greatly during the whole growth stage (Figures 5 and 6). At the beginning of the growth stage, the coverage of rice was low, resulting in low light transmission, and the number of stems and leaves under water control for RSI was

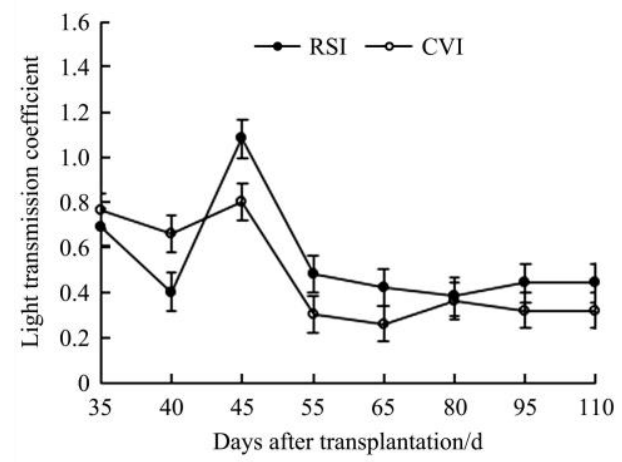

a. Year 2013 restricted, therefore light transmission coefficient and canopy light transmission was lower for RSI. Then the light transmission coefficient decreased and increased obviously at tillering stage. As the number of rice leaves was stable, the paddy field was completely covered in the later growth stage, the light transmission coefficient was affected greatly by water condition, and leaf area effect was gradually reduced. The light transmission coefficient reached the maximum at the end of tillering stage, and then decreased at jointing-booting stage, and kept rather stable at heading-flowering stage.

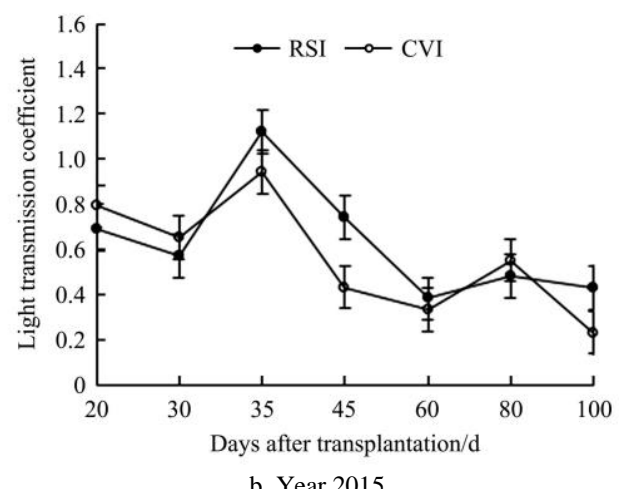

b. Year 2015

Figure 5 Dynamics of light propagation coefficient under different irrigation modes
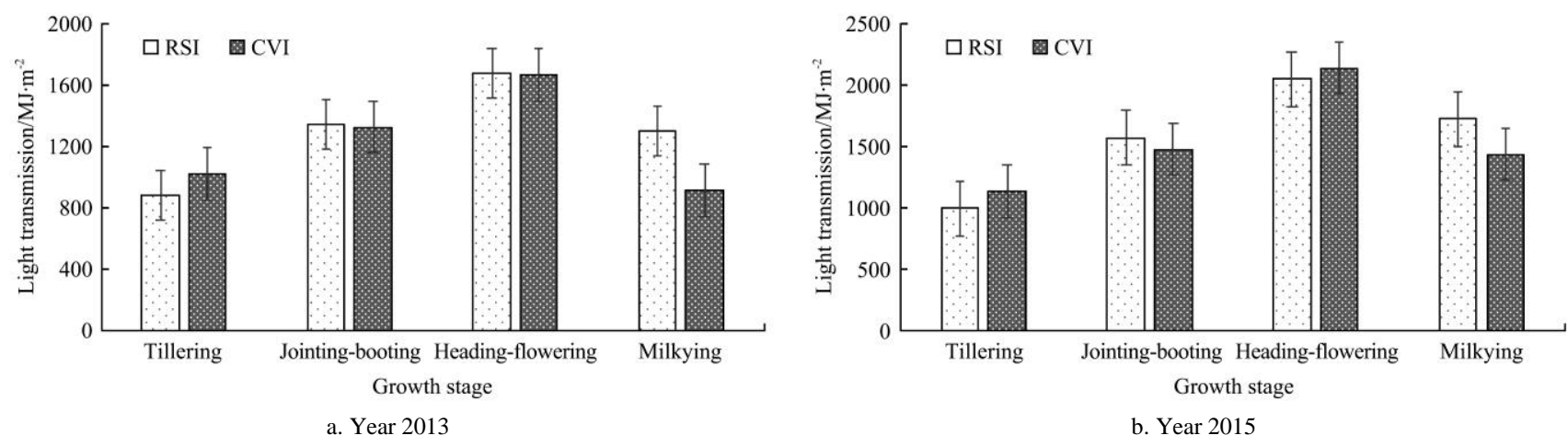

Figure 6 Dynamics of canopy light transmission under different irrigation modes

At tillering stage, the rice leaves were smaller and the ground coverage was lower, leading to lower canopy light transmission. The canopy light transmission under RSI was $13.4 \%$ and $12.1 \%$ lower than that under CVI in 2013 and 2015, respectively. At the jointing-booting stage, the amount of canopy light transmission increased significantly. This was due to the growth and increase of rice leaves and the increase of leaf area, which could be concluded from above results in Section 3.1. With the stability of the number of rice leaves, the canopy development gradually became complete, and the ground was completely covered by the late growth stage. The effect of leaf area on light transmission of the canopy was gradually reduced, while the effect of water began to increase. The gap of the light transmission amount between RSI and CVI was gradually reduced. The amount of canopy light transmission continued to increase, reaching the maximum at the heading-flowering stage. The maximum canopy light transmission was $1578 \mathrm{MJ} / \mathrm{m}^{2}$ and $1664 \mathrm{MJ} / \mathrm{m}^{2}$ for CVI and RSI in 2013, while it was $2045 \mathrm{MJ} / \mathrm{m}^{2}$ and $2133 \mathrm{MJ} / \mathrm{m}^{2}$ in 2015 . At the milking period, the canopy light transmission decreased with the leaves senescence of rice, and it decreased significantly under the CVI mode. The delay in aging under RSI treatment had a positive effect on maintaining a high light transmission during the late growth period.
According to regression analysis in Table 2, leaf area index $(y)$ and canopy light transmission $(x)$ of rice leaves had quadratic relationships both for RSI and CVI treatments, while the correlation coefficient for RSI was higher both in 2013 and 2015, showing extremely positive correlation.

Table 2 Regression analysis between leaf area index and canopy light transmission

\begin{tabular}{cclcc}
\hline Year & Treatment & \multicolumn{1}{c}{ Fitting equation } & \multicolumn{1}{c}{$R^{2}$} & $p$ \\
\hline \multirow{2}{*}{2013} & RSI & $y=-3526 x^{2}+10366 x-5904$ & 0.9722 & $<0.001$ \\
& CVI & $y=-140 x^{2}+796 x+439$ & 0.5289 & $<0.001$ \\
\hline \multirow{2}{*}{2015} & RSI & $y=2069 x^{2}-7399 x+7620$ & 0.9989 & $<0.001$ \\
& CVI & $y=-261 x^{2}+1460 x-149$ & 0.7390 & $<0.001$ \\
\hline
\end{tabular}

3.3 Dynamic change of photosynthetic and transpiration rate

Photosynthetic rate $\left(P_{n}\right)$ is an important factor affecting dry matter accumulation and yield formation of rice. Xia et al. ${ }^{[25]}$ have found that PAR (photosynthetically active radiation) was the most important ecological factor affecting $P_{n}$, also $P_{n}$ and transpiration rate $\left(T_{r}\right)$ had quadratic and linear relationships with PAR under different water level control treatments ${ }^{[26]}$.

The change of $P_{n}$ and $T_{r}$ under different irrigation modes in the main growth stages of rice was shown in Figure 7. In general, the $P_{n}$ and $T_{r}$ showed the similar change trend of firstly increasing and 
then decreasing, reaching the maximum at the heading-flowering stage, and reduced quickly to a lower level at milking stage. The regression analysis on $P_{n}$ and $T_{r}$ showed a good linear relationship (Table 3).

At tillering stage, $P_{n}$ under RSI was lower than that under CVI, while it was opposite for $T_{r}$. At jointing-booting stage, due to sufficient rainfall in southern China, the difference in soil moisture was small for RSI and CVI treatments, and the difference of $P_{n}$ for all treatments was not significant. The increasing rate of $P_{n}$ was $89.2 \%$ and $54.3 \%$ compared to the $P_{n}$ in tillering stage in 2013, and it was $68.9 \%$ and $62.5 \%$ in 2015 , respectively. The solar radiation was the largest at heading-flowering stage, therefore the photosynthesis was the strongest, and difference in transpiration caused by water difference was most obvious, therefore, the $P_{n}$

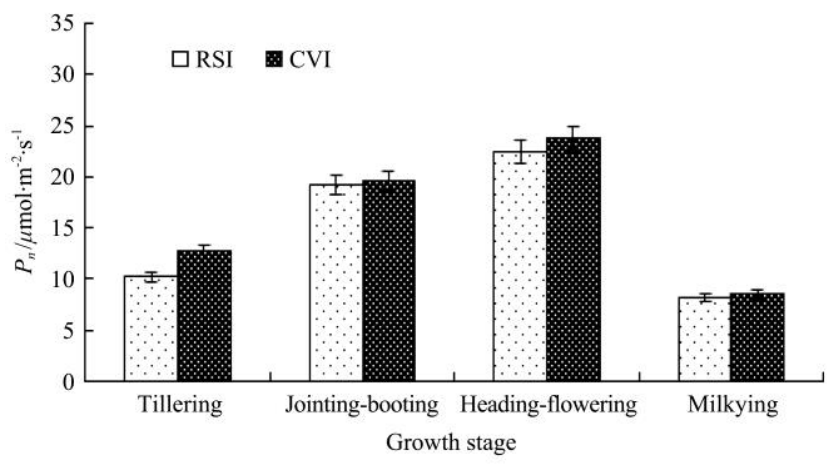

and $T_{r}$ reached the peak, with peak $P_{n}$ values of $22.5 \mu \mathrm{mol} /\left(\mathrm{m}^{2} \cdot \mathrm{s}\right)$, $23.7 \mu \mathrm{mol} /\left(\mathrm{m}^{2} \cdot \mathrm{s}\right)$ and peak $T_{r}$ values of $9.1 \mu \mathrm{mmol} /\left(\mathrm{m}^{2} \cdot \mathrm{s}\right)$, $10.9 \mathrm{mmol} /\left(\mathrm{m}^{2} \cdot \mathrm{s}\right)$ for RSI and CVI treatments in 2013, and peak $P_{n}$ values of $33.4 \mu \mathrm{mol} /\left(\mathrm{m}^{2} \cdot \mathrm{s}\right), 35.2 \mu \mathrm{mol} /\left(\mathrm{m}^{2} \cdot \mathrm{s}\right)$ and peak $T_{r}$ values of $10.3 \mathrm{mmol} /\left(\mathrm{m}^{2} \cdot \mathrm{s}\right), 11.8 \mathrm{mmol} /\left(\mathrm{m}^{2} \cdot \mathrm{s}\right)$ in 2015 , respectively. Also, the difference of $P_{n}$ and $T_{r}$ between RSI and CVI was maximum at heading-flowering stage. From the flowering stage to the milking stage, the chlorophyll content decreased significantly as shown in Section 3.1, the photosynthetic performance and activity of the leaves decreased, and the physiological activities decreased, thus the $P_{n}$ and $T_{r}$ decreased rapidly to a lower level, even was lower than that in tillering stage. The quadratic curve positive correlation of $P_{n}$ and $T_{r}$ with chlorophyll content also supports the above results (Table 3 ).

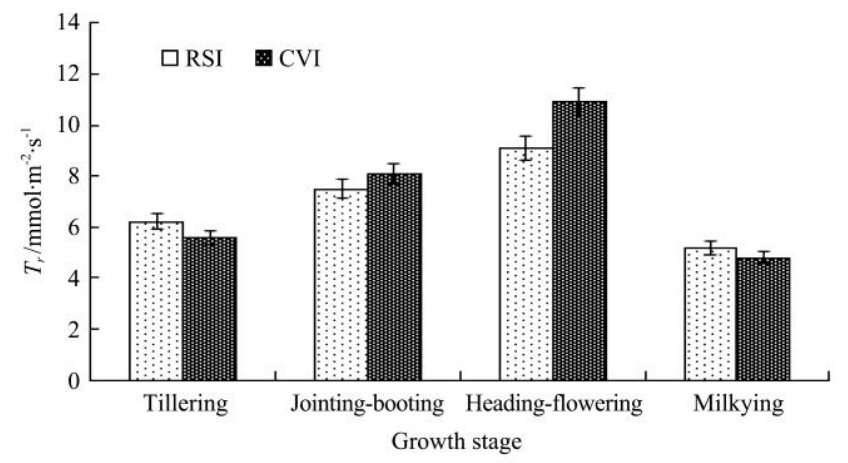

a. Year 2013
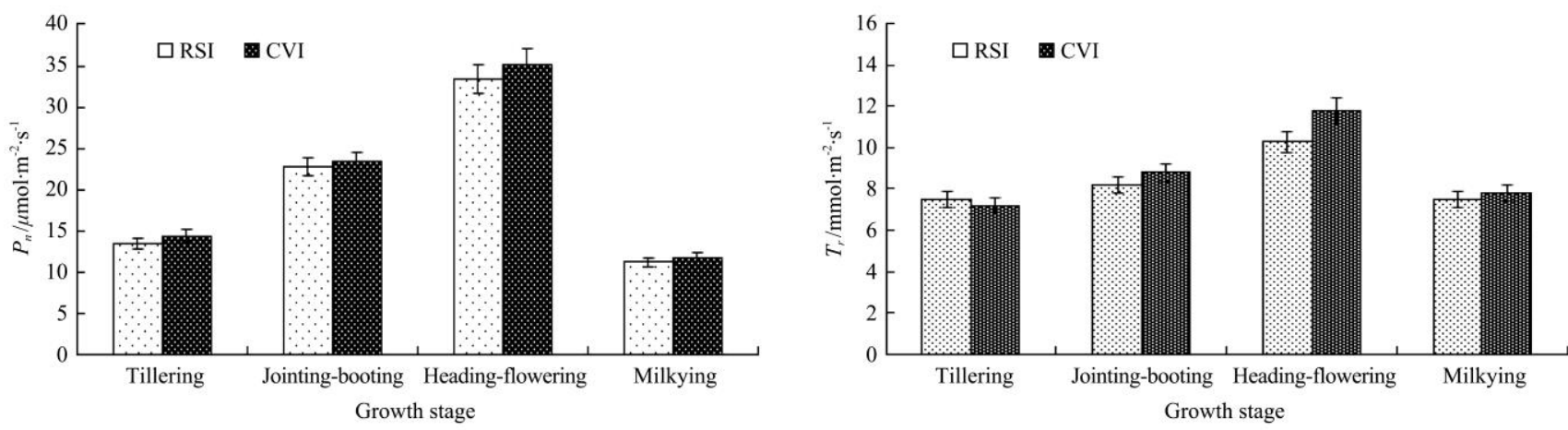

b. Year 2015

Figure 7 Dynamics of photosynthetic and transpiration rate

Table 3 Regression analysis between chlorophyll, $P_{n}$ and $T_{r}$

\begin{tabular}{|c|c|c|c|c|c|}
\hline Year & & Treatment & Fitting equation & $R^{2}$ & $p$ \\
\hline \multirow{6}{*}{2013} & \multirow{2}{*}{$P_{n}$ and chlorophyll } & RSI & $y=0.3422 x^{2}-8.3952 x+58.031$ & 0.9087 & $<0.001$ \\
\hline & & CVI & $y=0.2522 x^{2}-6.3575 x+47.368$ & 0.9850 & $<0.001$ \\
\hline & \multirow{2}{*}{$T_{r}$ and chlorophyll } & RSI & $y=0.0466 x^{2}-0.9896 x+10.415$ & 0.7778 & $<0.001$ \\
\hline & & CVI & $y=0.1335 x^{2}-3.5945 x+27.763$ & 0.9242 & $<0.001$ \\
\hline & \multirow{2}{*}{$T_{r}$ and $P_{n}$} & RSI & $y=0.312 x+1.756$ & 0.9129 & $<0.001$ \\
\hline & & CVI & $y=0.3467+1.6918$ & 0.9749 & $<0.001$ \\
\hline \multirow{5}{*}{2015} & \multirow{2}{*}{$P_{n}$ and chlorophyll } & RSI & $y=0.7851 x^{2}-42.937 x+597.98$ & 0.8636 & $<0.001$ \\
\hline & & CVI & $y=0.8396 x^{2}-46.022 x+642.11$ & 0.8411 & $<0.001$ \\
\hline & \multirow{2}{*}{$T_{r}$ and chlorophyll } & RSI & $y=0.2217 x^{2}-12.586 x+184.99$ & 0.7057 & $<0.001$ \\
\hline & & CVI & $y=0.4452 x^{2}-25.412 x+367.46$ & 0.7978 & $<0.001$ \\
\hline & $T_{r}$ and $P_{n}$ & RSI & $y=0.245 x+2.9317$ & 0.8747 & $<0.001$ \\
\hline
\end{tabular}

3.4 Characteristic of dry matter accumulation in aboveground part of rice

The accumulation of dry matter (DMA) in the aboveground part of rice with different water treatments is shown in Figure 8.
Totally speaking, DMA in panicle was highest, which was closely related to yield formation. Then followed by lower DMA in leaf, and DMA in stem was the lowest. The total DMA under CVI mode was slightly lower than that under RSI at the milking stage. 
The effect of irrigation mode on total DMA and the distribution in aboveground parts of leaf, stem and panicle was not obvious.

The DMA in stem and leaf was highest at heading-flowering stage, and dry matter in stem began to accumulate at jointing-booting stage, while the proportion was smallest. The dry matter in leaf began to accumulate at tillering stage till the end of growth stage, and DMA in panicle was concentrated at heading-flowering stage and milking stage, with higher content at milking stage, respectively, accounting for $68.9 \%$ and $75.3 \%$ under CVI and RSI in 2013, and $72.9 \%$ and $69.1 \%$ in 2015, respectively. The increasing rate of DMA in panicle from heading-flowering stage to milking stage was $61.2 \%$ and $93.6 \%$ in 2013 and $33.9 \%$ and $37.9 \%$ in 2015 . Therefore, the water condition under RSI was favorable for DMA in panicle compared to CVI.

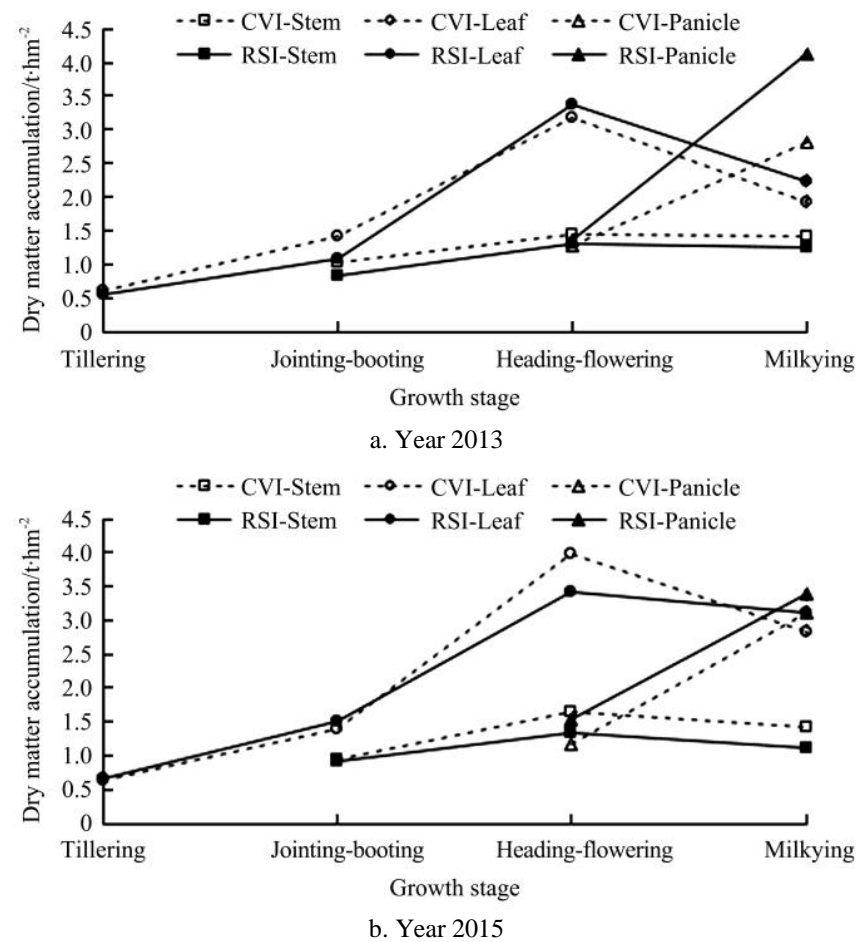

Figure 8 Dry matter accumulation in aboveground part of rice under different irrigation modes

\subsection{Multiple regressions on dry matter accumulation}

Taking total dry matter accumulation (DMA) as dependent variable, leaf area index (LAI), chlorophyll content (CC), canopy light transmission (LT), light transmission coefficient (TC), $P_{n}$, and $T_{r}$ were considered as independent variables, then multiple regression equation was constructed as Equation (1). It showed that the six variables could cover $90.3 \%$ of the dry matter accumulation change, of which the contribution on DMA of $X_{1}$ and $X_{3}$ factors were positive, while $X_{2}, X_{4}, X_{5}$ and $X_{6}$ were negative. After the significance test on this model, it was extremely significant $(F=13.9834$ Significance $F=0.00041)$ The significance test on coefficients of partial regression in Table 4 and Table 5 showed the canopy light transmission was extremely significant $(p<0.01)$, while light transmission coefficient and $P_{n}$ were significant $(p<0.05)$, other factors on dry matter accumulation was not significant.

$$
\begin{gathered}
Y=1.337 X_{1}-0.144 X_{2}+0.009 X_{3}-7.198 X_{4}-0.25 X_{5}-0.286 X_{6}+2.847 \\
\left(R^{2}=0.9031\right)
\end{gathered}
$$

where, $Y$ is dry matter accumulation, $\mathrm{t} / \mathrm{hm}^{2} ; X_{1}$ is LAI; $X_{2}$ is chlorophyll content, CCI; $X_{3}$ is canopy light transmission, $\mathrm{MJ} / \mathrm{m}^{2}$; $X_{4}$ is light transmission coefficient; $X_{5}$ is photosynthetic rate, $\mu \mathrm{mol} /\left(\mathrm{m}^{2} \cdot \mathrm{s}\right) ; X_{6}$ is transpiration rate, $\mathrm{mmol} /\left(\mathrm{m}^{2} \cdot \mathrm{s}\right)$.
Table 4 Significance test on coefficients of partial regression

\begin{tabular}{cccccc}
\hline Factor & $\begin{array}{c}\text { Standard } \\
\text { Error }\end{array}$ & t Stat & P-Value & $\begin{array}{c}\text { Lower Limit } \\
95 \%\end{array}$ & $\begin{array}{c}\text { Upper Limit } \\
95 \%\end{array}$ \\
\hline LAI & 1.0427 & 1.2826 & 0.2317 & -1.0214 & 3.6963 \\
CC & 0.0743 & -1.9320 & 0.0854 & -0.3116 & 0.0245 \\
LT & 0.0018 & 5.0935 & 0.0006 & 0.0049 & 0.0129 \\
TC & 1.5965 & -4.5085 & 0.0014 & -10.8091 & -3.5862 \\
$P_{n}$ & 0.0976 & -2.5563 & 0.0309 & -0.4704 & -0.0287 \\
$T_{r}$ & 0.5584 & -0.5129 & 0.6204 & -1.5495 & 0.9767 \\
\hline
\end{tabular}

\begin{tabular}{|c|c|c|c|c|}
\hline Factor & LT & $\mathrm{TC}$ & Pn & DMA \\
\hline LT & 1.0000 & & & \\
\hline TC & -0.3860 & 1.0000 & & \\
\hline$P_{n}$ & 0.8006 & -0.4073 & 1.0000 & \\
\hline DMA & $0.5845^{* *}$ & $-0.6630 *$ & $0.1984 *$ & 1.0000 \\
\hline
\end{tabular}

Table 5 Correlation coefficients between main factors of yield

From the above results, taking consideration of the main factors (LT, TC, and $P_{n}$ ) of dry matter accumulation, and then the optimal regression equation was constructed as Equation (2), and it was extremely significant ( $F=24.7908$ Significance $F=1.98 \mathrm{E}-05)$. The direct path coefficients of LT, TC and $P_{n}$ on DMA $\left(\mathrm{Py}_{1}, \mathrm{Py}_{2}\right.$, $\left.\mathrm{Py}_{3}\right)$ were calculated according to partial regression coefficient of independent variable multiply by standard deviation of independent variables, then divide standard deviation of dependent variables, thus as follows ${ }^{[27]}$,

$$
\begin{aligned}
& \mathrm{Py}_{1}=0.0082 \times 0.2184 / 2.8357=0.0006 \\
& \mathrm{Py}_{2}=-8.052 \times 8.5856 / 2.8357=-24.3789 \\
& \mathrm{Py}_{3}=-0.3040 \times 1.8542 / 2.8357=-0.1988 . \\
& Y=0.008 X_{3}-8.052 \mathrm{X}_{4}-0.304 \mathrm{X}_{5}+2.304 \quad\left(R^{2}=0.8611\right)
\end{aligned}
$$

It can be concluded that the direct effect of canopy light transmission on dry matter accumulation was greater, and light transmission coefficient and $P_{n}$ had negative effect on dry matter accumulation. Therefore, in order to maintain high rice yield, canopy light transmission should be increased during rice plant growth stage.

\section{Discussion}

There was little difference on leaf area index and chlorophyll content in rice leaves between the different water treatments. However, the water condition in RSI was favorable for delaying the decrease of leaf area index, which was conducive to the accumulation of photosynthetic products. Due to the re-watering, the chlorophyll content of RSI surpassed that of CVI at $45 \mathrm{~d}$ for a short while, resulting in compensation on leaf growth under RSI treatment. The solar radiation at heading-flowering stage was the strongest, and synthesis efficiency of chlorophyll was the highest, therefore the chlorophyll content reached the maximum.

The water condition for RSI was more conducive to the radiation penetrating the upper canopy to the lower part, improving the light transmission capacity of the canopy, and compensated for the negative impact caused by the reduction of rice leaves. The canopy light transmission under RSI was lower than that under CVI, which was mainly because the regulation of soil moisture under RSI treatment restricted the number of tillering and leaves of rice, which led to the inhibition of canopy development, therefore, the transmission of light by canopy was affected. At the heading-flowering stage, due to the accumulation of dry matter and photosynthesis increasing in rice, resulting in enhanced light 
transport capacity, and the canopy light transmission under RSI treatment exceeded that under CVI.

At the tillering stage, water was an indispensable condition for photosynthesis, and there was sufficient water for CVI treatment, therefore, the physiological activities were much more active, which was more conducive to the photosynthetic process. Compared to CVI, the $T_{r}$ value under RSI was slightly higher during tillering and milking stages when the transpiration was weak, while it was lower during jointing-booting and heading-flowering stages, illustrating that water condition under RSI restricted the transpiration process and reduced transpiration loss. The $P_{n}$ was not significantly reduced through photosynthesis was restricted by less soil moisture. The $P_{n}$ under RSI was lower than that under CVI, however, the increasing rate was higher, which was more conducive to the accumulation of photosynthetic products.

\section{Conclusions}

(1) The chlorophyll content and leaf area index showed a quadratic curve positive correlation and their change trends were similar, with increasing and then decreasing, reaching the maximum at heading-flowering stage. The water treatment under RSI was favorable for delaying the reduction of leaf area index, which was favorable for the accumulation of photosynthetic products.

(2) The light transmission coefficient reached the maximum at the end of tillering stage because of stable number of rice leaves, and then light transmission reached the maximum at the heading-flowering stage. Leaf area index and canopy light transmission had quadratic relationships and extremely positive correlation.

(3) Photosynthetic rate $\left(P_{n}\right)$ and transpiration rate $\left(T_{r}\right)$ showed the similar change trend, reaching the maximum at the heading-flowering stage, and they had quadratic curve positive correlation with chlorophyll content. The total dry matter accumulation in aboveground part under rain-water storage irrigation mode was higher than that under conventional irrigation. The dry matter accumulation in stem and leaf was highest at heading-flowering stage. The water condition under rain-water storage was favorable for dry matter accumulation in panicle.

(4) After multiple regression analysis on dry matter accumulation, leaf area index, chlorophyll content, canopy light transmission, light transmission coefficient, $P_{n}$ and $T_{r}$ could cover $90.3 \%$ of the dry matter accumulation change, and contribution of leaf area index and canopy light transmission factors were positive, while the rest were negative. The canopy light transmission, light transmission coefficient and $P_{n}$ were three main factors related to dry matter accumulation of rice.

\section{Acknowledgements}

This research was financially supported in part by the National Natural Science Foundation of China (Grant No. 52009044, 51779093), partly by the High-level Talent Research Project of North China University of Water Resources and Electric Power (Grant No. 201705017), partly by the National Key Research and Development Program (Grant No. 2019YFC0408803), and partly by Key Laboratory of Efficient Irrigation-Drainage and Agricultural Soil-Water Environment in Southern China (Hohai University), Ministry of Education (Grant No. 2017B20414-2). The authors are also thankful to the reviewers and the editor for their valuable comments, corrections and suggestions.

\section{[References]}

[1] Liu Z D, Zhang K, Huang C, Sun J S. Effects of different tillage and irrigation methods on photosynthetic characteristics of maize. Journal of Soil and Water Conservation, 2019; 33(4): 213-220. (in Chinese)

[2] Kiani-Pouya A. Changes in activities of antioxidant enzymes and photosynthetic attributes in triticale ( $\times$ Triticosecale, Wittmack) genotypes in response to long-term salt stress at two distinct growth stages. Acta Physiol Plant, 2015; 37: 72. doi: 10.1007/s11738-015-1819-6.

[3] Abbasi A R, Sarvestani R, Mohammadi B, Baghery A. Drought stress-induced changes at physiological and biochemical levels in some common vetch (Vicia sativa L.) Genotypes. Journal of Agricultural Science and Technology, 2014; 16(5): 505-516.

[4] Chen X, Hao M D. Low contribution of photosynthesis and water-use efficiency to improvement of grain yield in Chinese wheat. Photosynthetica, 2015; 53: 519-526.

[5] Carroll D A, Hansen N C, Hopkins B G, Dejonge K C. Leaf temperature of maize and crop water stress index with variable irrigation and nitrogen supply. Irrigation Science, 2017; 35: 1-12.

[6] Xu J Z, Peng S Z, Wei Z, Hou H J. Characteristics of rice leaf photosynthetic light response curve with different water and nitrogen regulation. Translations of the CSAE, 2012; 28: 72-76. (in Chinese)

[7] Li B, Meng Z J, Shen X J, Liu X F, Chang X. Improving photosynthesis and water use efficiency of winter wheat and summer maize by coupling alternate furrow irrigation and regulated water deficit. Journal of Irrigation and Drainage, 2018; 37(11): 8-14. (in Chinese)

[8] Wu Y L, Guo Q F, Luo Y, Tian F X, Wang W. Differences in physiological characteristics between two wheat cultivars exposed to field water deficit conditions. Russ. J. Plant Physiol., 2014; 61:451-459.

[9] Cui Y K, Tian Z W, Zhang X, Muhammad A, Han H M, Jiang D, et al. Effect of water deficit during vegetative growth periods on post-anthesis photosynthetic capacity and grain yield in winter wheat (Triticum aestivum L.). Acta Physiol Plant, 2015; 37: 196. doi: 10.1007/s11738-015-1944-2.

[10] Yang J C, Zhang J H, Huang Z L, Zhu Q S, Wang L. Remobilization of carbon reserves is improved by controlled soil-drying during grain filling of wheat. Crop Science, 2000; 40(6): 1645-1655.

[11] Xu J Z, Peng S Z, Wei Z. Effect of soil moisture regulation during tillering period on shoot dynamics of rice cultivated in plastic film mulched dryland and its simulation. Journal of Hohai University (Natural Sciences), 2010; 38(5): 511-515. (in Chinese)

[12] Peng S Z, Ding J L, Xu J Z, Liu F L. Experimentation of transpiration rate and influence factors of late rice. Water Saving Irrigation, 2005; 1 : 1-4. (in Chinese)

[13] Farooq M, Hussain M, Siddique K H M. Drought stress in wheat during flowering and grain-filling periods. Critical Reviews in Plant Sciences, 2014; 33(4): 331-349.

[14] Du Y F, Liu F, Liu K, Wu W P, Wang Y, Chen G H. Photosynthetic characteristics and yield of machine-transplanted rice in southern double-season rice areas under water-saving irrigation. Chinese Journal of Tropical Crops, 2019; 40(10): 2047-2053. (in Chinese)

[15] Wang Q J, Li M X, Chi L Y, Zhao H L, Jiang H. Effect of control irrigation on rice yield and quality. Journal of Northeast Agricultural University, 2009; 40: 5-8. (in Chinese)

[16] Peng S Z, Cai M, Kong W L, Xu J Z, Jin X P, Song J. Effects of water deficit in different growing stages on yield and dry matter of rice. Journal of Water Resources \& Water Engineering, 2012; 23(1): 10-13. (in Chinese)

[17] Liu F L, Peng S Z, Xu J Z, Ding J L. Characteristics of rice population under controlled irrigation condition. Journal of Shenyang Agricultural University, 2004; 35: 417-419. (in Chinese)

[18] Lei S, Wang C C, Huang Y, Huang S H, Fu R Z, Tang X R. Effect of controlled irrigation on soil temperature and dry matter accumulation of rice during tillering stage. Acta Agriculturae Boreali-Simica, 2016; 31(2): 153-158. (in Chinese)

[19] Zhu D J, Song Y, Huang H, Wang Y R. Effect of water stress in early stage on rice dry matter accumulation and $\mathrm{N}$ uptake and utilization. Journal of Anhui Agriculture Science, 2017; 45(28): 42-44, 57. (in Chinese)

[20] Shi H L, Yan Q Q, Zhang J S, Li C Y, Dou H T. Compensation effect of nitrogen fertilizer on photosynthetic characteristics and yield during cotton flowering boll-setting stage under non-sufficient drip irrigation. Acta Agronomica Sinica, 2018; 44(8): 1196-1204. (in Chinese)

[21] Guóth A, Tari I, Gallé Á, Csiszár J, Horváth F, Pécsváradi A, et al. 
Chlorophyll a fluorescence induction parameters of flag leaves characterize genotypes and not the drought tolerance of wheat during grain filling under water deficit. Acta Biol. Szegediensis, 2009; 53(1): 1-7.

[22] Liu H Y, Wang X D, Wang D H, Zou Z R, Liang Z S. Effect of drought stress on growth and accumulation of active constituents in Salvia miltiorrhiza Bunge. Industrial Crops and Products, 2011; 33(1): 84-88.

[23] Shahzad A, Xu Y Y, Jia Q M, Irshad A, Wei T, Ren X L, et al. Cultivation techniques combined with deficit irrigation improves winter wheat photosynthetic characteristics, dry matter translocation and water use efficiency under simulated rainfall conditions. Agricultural Water Management, 2018; 201: 207-218.

[24] Lyu G D, Wang C, Jin X M, Xu J L, Wang R X, Sun X Y, et al. Effects of water-nitrogen interaction on dry matter, nitrogen accumulation and yield of winter wheat. Chinese Journal of Applied Ecology, 2020; 31(8): 2593-2603. (in Chinese)

[25] Xia J B, Zhang S Y, Guo J, Rong Q Q, Zhang G C. Critical effects of gas exchange parameters in Tamarix chinensis Lour on soil water and its relevant environmental factors on a shell ridge island in China's Yellow River Delta. Ecological Engineering, 2015; 76: 36-46.

[26] Xiao M H, Li Y Y, Lu B, Miao Z M. Response of physiological indicators to environmental factors under water level regulation of paddy fields in southern China. Water, 2018; 10(12): 1772. doi: 10.3390/ w10121772.

[27] Li Y Y, Shao X H, Li D X, Xiao M H, Hu X J, He J. Effect of water and nitrogen coupling on growth, physiology and yield of rice. Int J Agric \& Biol Eng, 2019; 12(3): 60-66. 